\title{
The development of a model for dealing with secondary traumatic stress in mental health workers in Rwanda
}

\author{
Jean Damascène Iyamuremye ${ }^{a, 1}$, Petra Brysiewicz ${ }^{b, *}$ \\ ${ }^{a}$ Mental Health Nurse Specialist, Ministry of Health, Mental Health Division, Kigali, Rwanda \\ ${ }^{\mathrm{b}}$ School of Nursing \& Public Health, University of KwaZulu-Natal, King George V Avenue, Durban, South Africa
}

\section{A R T I C L E I N F O}

Article history:

Received 16 February 2015

Accepted 24 February 2015

Available online 19 August 2015

Keywords:

Genocide

Mental health workers

Rwanda

Secondary traumatic stress

\begin{abstract}
A B S T R A C T
Introduction: Mental health workers who listen to stories of fear, pain and distress of traumatised clients may develop deleterious emotional, cognitive and physical consequences (Cairns, 2007). This phenomenon has been called secondary traumatic stress (STS) (Perez, Jones, Englert, \& Sachau, 2010). Rwanda is well-known for the 1994 genocide, with the death of hundreds of thousands of people in a planned campaign of violence. Numerous mental health workers operating in Rwanda were also victims of the violence and it has been suggested that there is a high level of STS in mental health workers in
\end{abstract} Rwanda (Iyamuremye \& Brysiewicz, 2008).

Aim: To develop a comprehensive model to manage the effects of STS in mental health workers operating in Rwanda.

Method: An action research project was initiated to develop this model and data for the model was collected through individual interviews with mental health workers (nurses, doctors, psychologists, trauma counsellors and social workers) as well as a quantitative tool measuring secondary traumatic stress (Trauma Attachment Belief Scale) in these health workers.

Results: The Intervention Model to Manage Secondary Traumatic Stress (IMMSTS) was synthesised from these findings and includes preventive, evaluative and curative strategies to manage STS in mental health workers in Rwanda at the individual, social and organisational levels.

Conclusion: The model will offer mental health professionals an effective framework for addressing the issue of STS.

Copyright $\odot$ 2015, The Authors. Production and hosting by Elsevier B.V. on behalf of Johannesburg University. This is an open access article under the CC BY-NC-ND license (http://creativecommons.org/licenses/by-nc-nd/4.0/).

\footnotetext{
* Corresponding author. Tel.: +27 31 2601281, +27 837855069 (mobile).

E-mail addresses: iyadamas@gmail.com (J.D. Iyamuremye), brysiewiczp@ukzn.ac.za (P. Brysiewicz).

1 Tel.: +250 782299718 .
}

Peer review under responsibility of Johannesburg University. http://dx.doi.org/10.1016/j.hsag.2015.02.006

1025-9848/Copyright @ 2015, The Authors. Production and hosting by Elsevier B.V. on behalf of Johannesburg University. This is an open access article under the CC BY-NC-ND license (http://creativecommons.org/licenses/by-nc-nd/4.0/). 


\section{Introduction}

Rwanda is known throughout the world for the 1994 genocide where up to one million people were massacred during the 100-day genocide against the Tutsi. The recovery process has presented huge national and personal challenges for survivors (Schaal \& Elbert, 2006). During the genocide, Rwandan women were subjected to sexual violence on a massive scale committed by elements of the notorious Hutu militia groups, well-known as the Interahamwe (Mukamana \& Brysiewicz, 2008). Mental health workers who listen to these stories of fear, pain and distress of traumatised clients may develop their own deleterious emotional, cognitive and physical consequences (Cairns, 2007). This phenomenon has been called STS (Perez et al., 2010). Since numerous mental health workers operating in Rwanda are themselves victims of trauma, it is imperative to ensure that appropriate psychological support services are developed to help them deal with STS. A pilot study showed that there was a high level of STS in mental health workers in Rwanda which warranted further intervention (Iyamuremye \& Brysiewicz, 2008).

The emotional consequences of working with traumatised individuals are visible in diverse ways, namely STS (Stoesen, 2007), compassion fatigue (Bride, Radey, \& Figley, 2007) and vicarious traumatisation (Pearlman \& McKay, 2008). Mental health workers may feel negative changes in their professional functioning, self and worldviews, sense of security, self-capacities and psychological needs as a result of indirect exposure to STS (Shah, Garland, \& Katz, 2007). The impact of STS on mental health workers in Rwanda and the insufficient support system need to be investigated, as mental health workers who are overburdened with work, stress and their own traumas have few resources left to care for and comfort others (Iyamuremye \& Brysiewicz, 2008). Unfortunately, most mental health workers are unaware of the nature and extent of STS, lack access to supportive resources and have little or no training about how to recognise symptoms in themselves and others, or how to respond to the resulting distress (Satkunanayagam, Tunariu, \& Tribe, 2010).

Although attention has been paid to the process of healing primary victims of trauma (Bicknell-Hentges \& Lynch, 2009), an enquiry into the therapeutic practice of mental health workers helping traumatised patients shows that very little has been done to manage the trauma of secondary victims. The aim of this study was to develop a comprehensive model which integrated primary, secondary and tertiary interventions in managing the effects of STS in mental health workers operating in Rwanda.

\section{Development of the model}

The Intervention Model to Manage Secondary Traumatic Stress (IMMSTS) was developed by using an action research design with mixed methodology. The researchers attempted to remain true to the mutually collaborative action research approach (Koshy, 2010) and ensured that health professionals were encouraged to be actively involved in the change process. At the beginning of the study, a research team consisting of experts in mental health care was established in keeping with the mutually collaborative action research approach. Inclusion criteria were that they had to hold either a qualification as a medical doctor, psychiatrist, psychologist, mental health nurse, social worker or trauma counsellor and expressed interest in being involved in the project. The research team members who guided the entire research process were involved in all aspects of the planning and implementation of the project. It was anticipated that once the research was completed, they would take a leading role in continuing the process of implementing the newly developed IMMSTS and leading the possible change in practice.

The research study comprised four cycles. Cycle 1 was the establishment of the research team and collection of quantitative descriptive data measuring the extent of STS using the Trauma Attachment Belief Scale (Pearlman, 2003). The results from this cycle then informed the questioning in Cycle 2 with the collection of qualitative data through individual interviews with mental health workers including nurses, doctors, psychologists, trauma counsellors and social workers regarding their experiences of STS (Iyamuremye \& Brysiewicz, 2012). A summary of the main findings from these two cycles are presented in Box 1.

Cycle 3 was an amalgamation of the findings from Cycle 1 and 2, as well as relevant literature, to develop the IMMSTS (see Fig. 1); this process was guided by Taylor-Powell and Henert (2008). The key elements included in the IMMSTS were preventive, evaluative and curative strategies to manage STS in mental health workers in Rwanda. In the process of generating the model, the research team started by describing what the model was trying to represent and to identify and describe the concepts active in the domain of STS management and then analyse them in terms of the phenomenon of interest. The research team also attempted to develop a visual representation of the IMMSTS. They attempted to use the idea of an algorithm as a way of visually presenting the IMMSTS because in the mental health practice staff are familiar with the use of algorithms. Cycle 4 was the implementation of the IMMSTS. After each cycle the research team reflected on the data obtained in the previous cycle and planned and refined the following cycle.

Permission to carry out the study was obtained prior to the initiation of data collection from the authorities of mental health services in Rwanda and the research committee of the University of KwaZulu-Natal, South Africa (the researcher was a student). Written consent was given by the participants; anonymity and confidentiality were maintained. Owing to the sensitive nature of the subject matter being discussed, the researchers were aware of the need to provide psychological support should it be necessary, and they had the appropriate skills to do so. The issue of ownership of the data and the research team members' role in the study was negotiated at the beginning of the study. 


\section{Box 1}

\section{Findings from Cycles 1 and 2.}

Cycle 1

Aim: To determine the extent of secondary traumatic stress in mental health workers in Rwanda using the Trauma Attachment Belief Scale (TABS).

Design: A quantitative design was used with total of 180 participants selected by means of convenience sampling. Data was collected using self-reported questionnaires which included demographic data and the Trauma Attachment Belief Scale (TABS). The TABS is made up of 84 items and participants were required to respond to each item using a 6-point Likert Scale. The TABS has demonstrated validity and reliability as it has been used in previous studies (Iyamuremye \& Brysiewicz, 2010b). The overall reported reliability (Cronbach's alpha) of the TABS is 0.98 (Pearlman, 2003). A total of 200 questionnaires was distributed with a response rate of $90 \%(n=180)$.

Findings: $67.2 \%$ of the respondents were female and $32.7 \%$ were male. The majority of participants $(73.8 \%)$ had personally experienced the events of the genocide, $10 \%$ had experienced accidental disaster in their past, 7.7\% had experienced emotional and psychological abuse, $7.2 \%$ reported that they had experienced some kind of natural disaster (e.g. flood, earthquake) and 2.2\% reported physical abuse as a child. A mean TABS score of 77.0 sd 1.2 was found in the participants and Pearlman (2003) suggested that the cut-off point for secondary traumatic stress be 50 , thus reflecting that the participants were above the cut-off levels for significant traumatisation and at risk of secondary traumatic stress (Iyamuremye \& Brysiewicz, 2010b).

Cycle 2

Aim: To explore mental health workers' experiences of secondary traumatic stress.

Design: A qualitative design was used and 30 unstructured individual interviews were conducted to investigate the experiences of secondary traumatic stress in mental health workers working in four mental health services. A total of 30 mental health workers was interviewed over a period of three weeks. The sample for this cycle comprised nurse managers, medical doctors, social workers, trauma counsellors, psychologists and psychiatric nurses.

Findings: The three main findings which underpinned the model's assumptions are as follows:

1 Stress: "Mental health work is really frightening. I began this work here as a new psychiatric nurse and I prayed for six months on the way to work. It's traumatic and terrifying in a work environment like this because it's pressure and high stressful. You've got so many things happening at one time and there is risk of all kinds of violence."
2 Lateness of onset: "I worked with one client who was being sadistically abused during 1994 genocide against Tutsi in Rwanda. Her situation seemed so desperate that I became more and more involved. I gave her my home phone number and accepted calls at any time. My cbout my lack of boundaries; other services providing support were frustrated by my need to be present. It didn't matter what anyone told me, I couldn't stop. I became angry and exhausted."

3 Seriousness of impact of stress: "You take it [the stress] home and you find that at home, you are not the person who you know yourself to be. You are short-tempered, you are agitated, you are irritated, you become aggressive yourself at home." (Iyamuremye \& Brysiewicz, 2012).

\section{Model assumptions}

The participants in the research study decided that in order for the model to be useful, the following assumptions had to be made.

- Since most Rwandans had personally experienced major losses or life-shattering events in the 1994 genocide, mental health workers in Rwanda are vulnerable to STS and its effects.

- Often mental health workers do not realise that they are suffering from STS until it is too late and they are already affected.

- The effects of STS can be serious, devastating and everlasting.

\section{Model description}

The IMMSTS has three major components, namely 1) providing STS preventive interventions; 2) providing STS risk assessment interventions; and 3) treatment component providing curative care and STS management/treatment interventions for mental health workers. These components originated from the quantitative findings of cycle 1 , the qualitative data of cycle 2 and the relevant supporting literature. Each concept was evaluated based on whether it seemed relevant to the management of secondary traumatic stress and whether it seemed useable when presented to participants. The IMMSTS illustrates directional relationships and these are indicated by uni-directional arrows going from the variable to another variable on which it is thought to exert its influence (see Fig. 1).

\subsection{Prevention component}

Providing STS preventive strategies is about protecting mental health workers from STS when dealing with traumatised clients. For the purpose of the IMMSTS, there are two types of preventive interventions involved in the management of STS. The first involves improving self-awareness and connection by providing education and training on STS, as well as 


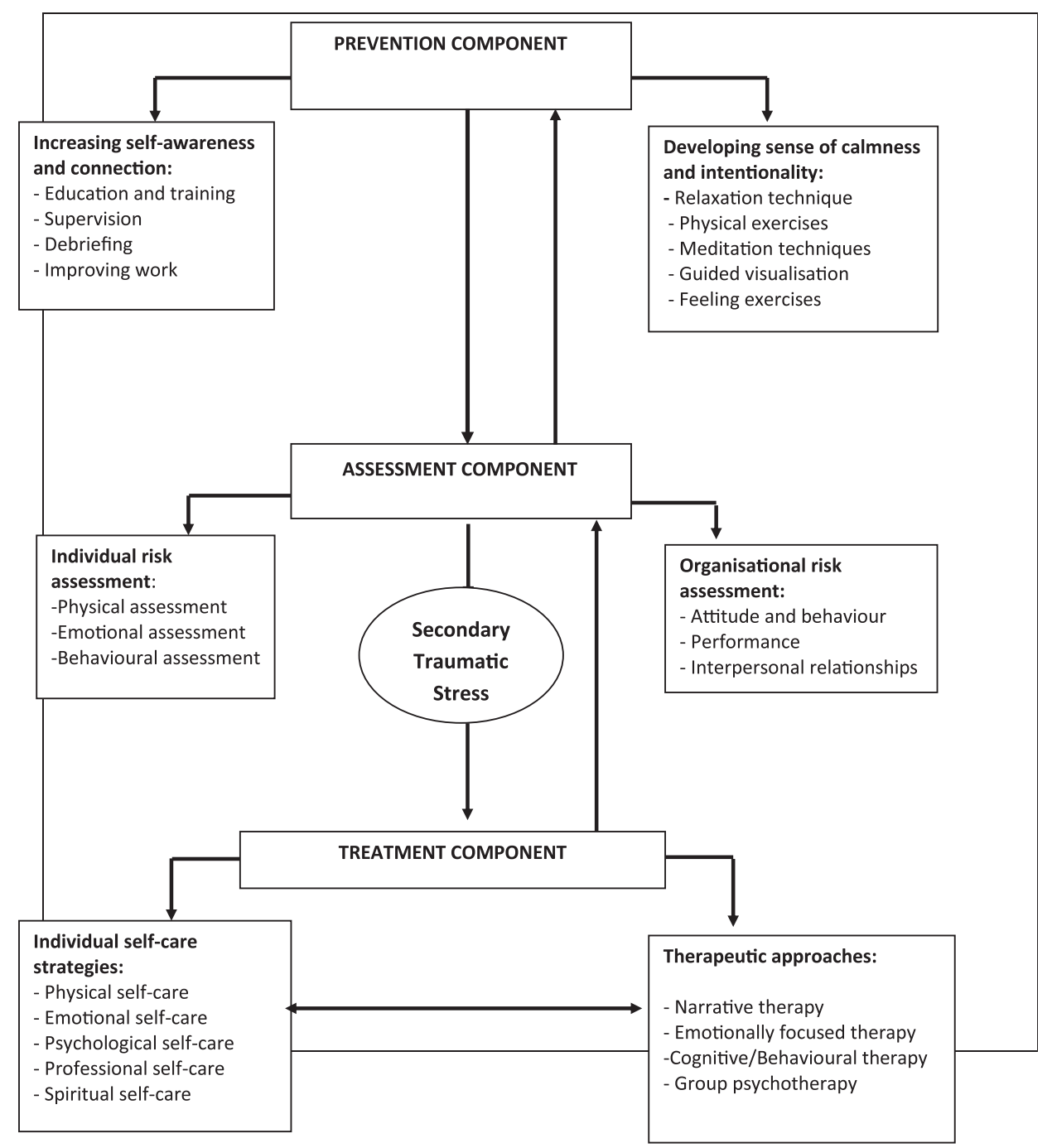

Fig. 1 - Intervention model to manage secondary traumatic stress (Iyamuremye \& Brysiewicz, 2010a).

supervision and debriefing, and improving work conditions by providing adequate communication and ensuring adequate resources and support systems (Hanna \& Romana, 2007). The second involves developing a sense of calmness and intentionality by means of personal and professional strategies which encourage relaxation techniques, physical activities, meditation techniques, guided visualisation and feeling exercises.

\subsection{Increasing self-awareness and connection}

One of the ways STS affects mental health workers is that it leaves them with a sense of disconnected isolation. A common symptom is the progressive loss in their sense of connection to themselves and to others. Many mental health workers become increasingly isolated as their symptoms intensify. As one participant explained:

When it's really bad I just shut off completely from everything I do, I just kind of retreat into myself and I don't really feel anything. I don't socialise, I don't do anything, I just kind of sit and try and work through it on my own.

Some activities such as education, supervision, meditation, relaxation, debriefing and improving the work environment are necessary to increase self-awareness and connection in mental health workers.

\subsection{Developing a sense of calmness and intentionality}

Calmness and intentionality in the context of STS management refers to mental health workers being able to witness the traumatic events and suffering of their clients and emerge from these experiences having made use of positive, adaptive coping strategies (Mikolajczak, Petrides, \& Hurry, 2009). Activities to develop a sense of calmness and intentionality in mental health workers include relaxation techniques, physical exercises, meditation techniques, and feeling exercises. A participant said in this regard: 
When I am having a bad day all I need to do is walk through the garden outside the service, and see the flowers. My heart sings again with their courage and I feel lucky and happy to be me.

\subsection{Assessment component}

Being in the mental health profession requires careful moment-to-moment self-monitoring. Symptoms of STS can be the same as those experienced by the direct victims of trauma including increased fatigue or illness, social withdrawal, reduced productivity, feelings of hopelessness, despair, nightmares, feelings of re-experiencing the event, having unwanted thoughts or images of traumatic events and anxiety, excess vigilance, avoidance of people or activities, or persistent anger and sadness (Stoesen, 2007).

A participant explained:

Sometimes after a session with a client, I will be traumatised ... I will feel overwhelmed, and I can remember a particular situation with a traumatised client where I just didn't want to hear any more of her stories about what actually happened. The client seemed to want to continue to tell me these [stories] over and over and I remember just feeling almost contaminated, like, you know, like I was myself traumatised. You know?

Risk assessment strategies can focus on either the individual or the organisation.

\subsection{Individual STS risk assessment}

STS affects mental health workers in different ways. The experience of STS can cause unusual and dysfunctional behaviour and contribute to poor physical and mental health. There are three major categories of individual assessment for secondary trauma risk, namely physical assessment, emotional assessment and behavioural assessment. A participant explained this as following:

I'm stressed all the time when I arrive at my work. My thing is not having enough time to spend with each patient. I think that is what gets me. And then when I get home, it's like, "Did I do right by that patient?" It may be one particular patient that was sick and it just spins off for the rest of the day.

Another participant said:

I feel more tired out of amount to the work that I have done if it has been a really bad day. I feel particularly exhausted if I have had numerous negative encounters, be it staff members or patients. Sometimes it feels like you are in it all by yourself ... and you are trying to wade through mud and sinking fast.

\subsection{Organisational STS risk assessment}

When assessing the risk of STS in mental health services, three major categories of symptoms should be taken into account. These are work performance assessment, interpersonal relationship assessment and staff attitude and behaviours. A participant explained:
The work environment is sometimes more traumatic on [to your] mental health than the traumatic stories we hear about ... and then unfortunately it takes your attitude of what has been happening at work ... you take it home and you find that at home, you are not the person who you know yourself to be. You are short-tempered, you are agitated, you are irritated, you become aggressive yourself at home.

Other participants:

Sometimes it gets so busy that I don't have the time to take a moment to calm myself and when I go to the next patient I feel like I get mad at them for being sick, for being there. It doesn't matter to me why they are here - the stress has gotten to me.

The excessive number of patients in the mental health service caused by increased acuity and lack of mental health staff made me feeling as if there is too little to fill all of the gaps.

\subsection{Treatment component}

Providing curative care and treatment for STS management is part of tertiary prevention of STS. In caring for the mental health workers experiencing STS two major interventions must be provided simultaneously. These interventions are individual self-care/self-management and therapeutic management. One participant said:

It would be nice to have a guideline to give you ideas on what to do and how to do [it] during stressful case.

\subsection{Individual self-care/self-management}

Shapiro, Brown, and Biegel (2007) describe the practice of selfcare as involving both self-awareness and self-regulation in the service of balancing many factors including psychological, physical and spiritual needs; connecting between self and others; and balancing one's personal and professional lives. Strategies to improve self-care are physical self-care, psychological and emotional self-care, spiritual self-care and professional self-care (Kearney, Weininger, \& Vachon, 2009). One participant said:

I have found that while working in mental health service I constantly have to take the time in order to take care of myself. I do this by enjoying time with friends, watching kids play in the park. I also take the time out to play and have vacations from here. Without this balance, I think it would be very easy to develop secondary traumatic stress and that I have to hide away in order to protect myself.

\subsection{Offering STS therapeutic approaches}

Suggestions for reducing the effects of STS include adherence to a therapy contract with clear goals, rules and boundaries, specialised training to raise awareness and recognition of STS (Goldblatt, 2009). Therapeutic approaches to manage STS include narrative therapy, emotional focused therapeutic approaches, cognitive behavioural therapies, and group therapy (Osofsky, Putnam, \& Lederman, 2008). 
It just sort of comes when you least expect it, you'll suddenly start thinking [about an event] ... and all of the thoughts and feelings that you had at that time... If we say we would like counselling, you know, I feel we should get it within a week of asking. Not two to three months down the line, and it has gone ... when we dealt with it. We want it when we ask for it.

\subsection{Implementation and evaluation of model}

The developed IMMSTS was implemented in one mental health service and the implementation of the model was evaluated after six weeks. A participatory approach was used to implement the developed model and after initial hesitance regarding the model, the mental health workers moved towards a shared view of what should be changed in managing secondary traumatic stress in mental health workers. They also tried to use the different interventions stipulated in the model and discussed the practicability of these interventions in the services.

After the implementation cycle the participants were asked to evaluate the implementation of the model according to the objectives of the study. The data was collected in a workshop held with mental health workers, managers and research team members where they were asked whether they felt the model had been worthwhile and whether there had been any change in their attitude. During this evaluation process the mental health professionals reported that they had already started to notice a change in coping with their stress when working with traumatised clients or other psychiatric patients.

\section{Reflections, limitations, and areas for further research}

By the end of the research study, a number of the participants initiated discussions with the researcher regarding STS and there appeared to be a greater acceptance of the reality of STS in Rwanda. The participants also said that the research had changed what they thought was important when managing their work-related stress and had also highlighted their own weaknesses as well as weaknesses in the mental health service. Some of the research team members proudly described how the IMMSTS had "worked" and how it contained all the information needed to manage STS in their institutions. This intervention model may thus serve as a frame of reference to facilitate and assist mental health workers who experience STS and hopefully increase awareness of the implication of STS.

One limitation of the study was that it could not be generalised as the study was only carried out in mental health services situated in Kigali City. The fact that the IMMSTS was implemented in one mental health service during a six-week period may also have restricted the impact of the IMMSTS. The usefulness and efficacy of this IMMSTS, as well as its possible use in settings other than mental health services, warrants further research.

There is a need to evaluate this intervention model to manage STS in mental health workers in Rwanda with a view to replicating the study on a large scale within the country and in the East African region.

In order to see how sustainable the model is over time, these interventions need to be translated into active ongoing coping activities to be conducted at the individual, group and organisational levels. Organisational responses, such as creating an organisational culture that acknowledges the potential for secondary traumatic stress, may help mental health workers to deal with secondary traumatic stress.

\section{Conclusion}

The model to manage STS is an essential component in rendering effective mental health care to traumatised clients and other psychiatric patients. The model can offer mental health professionals an effective framework for addressing the issue of STS. The implementation of the model needs a commitment by all role players in the mental health sector operating in Rwanda.

\section{Significance of work}

Numerous mental health workers operating in Rwanda were also victims of trauma; it is thus imperative to ensure that appropriate psychological support services are developed to assist them to deal with their secondary traumatic stress.

\section{Authors' contributions}

The study was conceptualised, carried out and analysed by both authors. J.D.I physically collected data and PB was the research supervisor. Both authors drafted the manuscript.

\section{R E F E R E N C E S}

Bicknell-Hentges, L., \& Lynch, J. J. (2009). Everything counsellors and supervisors need to know about treating trauma. In Paper based on a presentation at the American Counselling Association Annual Conference and Exposition. New York City: Charlotte.

Bride, B. E., Radey, M., \& Figley, C. R. (2007). Measuring compassion fatigue. Clinical Social Work Journal, 35(3), 155-163.

Cairns, K. (2007). Caring for the carers: Preventing and managing secondary traumatic stress. Basingstoke, England: Palgrave Macmillan. Retrieved from www.csa.com.

Goldblatt, H. (2009). Caring for abused women: impact on mental health workers' professional and personal life experiences. Journal of Advanced Nursing, 65(8), 167-176.

Hanna, D. R., \& Romana, M. (2007). Debriefing after a crisis Nursing Management, 38(8), 38-47.

Iyamuremye, J. D., \& Brysiewicz, P. (2008). Exploring secondary traumatic stress experienced by mental health workers working in mental health service in Rwanda (Unpublished Masters Dissertation). South Africa: University of KwaZulu Natal.

Iyamuremye, J. D., \& Brysiewicz, P. (2010a). The development of an interventional model to manage secondary traumatic stress in mental health workers in Rwanda (Unpublished PhD Thesis). South Africa: University of KwaZulu Natal. 
Iyamuremye, J. D., \& Brysiewicz, P. (2010b). Exploring secondary traumatic stress in mental health nurses working in Kigali, Rwanda. Africa Journal of Nursing and Midwifery, 12(2), 96-106.

Iyamuremye, J. D., \& Brysiewicz, P. (2012). Challenges encountered by mental health workers in Kigali, Rwanda. Africa Journal of Nursing and Midwifery, 14(1), 63-75.

Kearney, M. K., Weininger, R. B., \& Vachon, M. L. S. (2009). Selfcare of physician caring for patients at the end of Life: "being connected. A key to my survival. Journal of American Medical Association, 301(11), 1155-1164.

Koshy, V. (2010). Action research for improving educational practice. A step-by-step guide (2nd ed.). London: Sage.

Mikolajczak, M., Petrides, K. V., \& Hurry, J. (2009). Adolescents choosing self-harm as an emotion regulation strategy. The protective role of trait emotional intelligence. British Journal of Clinical Psychology, 48(4), 181-193.

Mukamana, D., \& Brysiewicz, P. (2008). The lived experience of genocide rape survivors in Rwanda. Journal of Nursing Scholarship, 40(4), 379-384.

Osofsky, J., Putnam, F., \& Lederman, C. (2008). How to maintain emotional health when working with trauma. Juvenile and Family Court Journal, 58(4), 63-72.

Pearlman, L. A. (2003). Trauma and attachment belief scale. Los Angeles: Western Psychological Services (WPS).

Pearlman, L. A., \& McKay, L. (2008). Understanding and addressing vicarious trauma. Headington Institute. Retrieved from www. headington-institute.org.
Perez, L. M., Jones, J., Englert, D. R., \& Sachau, D. (2010). Secondary traumatic stress and burnout among law enforcement investigators exposed to disturbing media images. Journal of Police and Criminal Psychology, 25(2), 113-124.

Satkunanayagam, K., Tunariu, A., \& Tribe, R. (2010). A qualitative exploration of mental health professionals' experience of working with survivors of trauma in Sri Lanka. International Journal of Culture and Mental Health, 3(5), 43-51.

Schaal, S., \& Elbert, T. (2006). Ten years after the genocide: trauma confrontation and posttraumatic stress in Rwandan adolescents. Journal of Traumatic Stress, 19(4), 95-105.

Shah, S. A., Garland, E., \& Katz, C. (2007). Secondary traumatic stress: prevalence for humanitarian aid workers in India. Traumatology, 13(2), 59-70.

Shapiro, S. L., Brown, K. H., \& Biegel, G. M. (2007). Teaching selfcare to caregivers: effects of mindfulness-based reduction on the mental health of therapist secondary traumatic stress in training. Training and Education of Professional Psychology, 1(6), 105-115.

Stoesen, L. (2007). Recognizing secondary traumatic stress. NASW News, 52(6), 4-12.

Taylor-Powell, E., \& Henert, E. (2008). Developing a logic model: Teaching and training guide. Madison, WI: University of Wisconsin, Extension, Cooperative Extension, Program Development and Evaluation. Retrieved from http://www. uwex.edu/ces/pdande. 